\title{
Reflection Photoelastic Stress Analysis of a Dental Bridge
}

\author{
J. W. FARAH and R. G. CRAIG \\ School of Dentistry, University of Michigan, Ann Arbor, Michigan 48104, USA
}

The stress distribution on the surface of a four unit gold bridge was determined by reflection photoelasticity. The highest stress concentration was at the soldered joints. The distribution of stress was a function of the support of the abutment teeth. Good support caused the bridge to function as one that was fixed at both ends, whereas poor support caused it to function as a cantilever beam.

In stress analysis applications emphasis is placed on careful determination of the stresses for the improvement of design. In nondestructive testing importance is placed on reliability and quality, and as a result of this, observation of surface strains is of interest.

Earlier photoelastic studies by El-Ebrashi et al 1-7 concerned, for the most part, two dimensional photoelasticity. In two dimensional studies a plastic model must be built, whereas the photoelastic coating method has the advantage of using the structure itself.

The technique of photoelastic coatings is basically a method that provides a visual display for the observation and measurement of stress distribution on the surface of parts under load. ${ }^{8}$ In this study a four unit posterior gold bridge was coated and the magnitudes of the strains were recorded at several locations as a function of load and position of loading.

\section{Materials and Methods}

MATERIALS.-A reflection polariscope was used to record the isochromatic and iso-

This investigation was supported, in part, by USPHS Research Grant DE-01817 from the National Institute for Dental Research, National Institutes of Health, Bethesda, Md and by the Horace H. Rackham School of Graduate Studies Faculty Research Grant, Project No. NS-18.

Presented at the 48th General Session of the IADR, March 1970, New York, NY.

Received for publication May 25, 1970. clinic fringes. The reflection polariscope consists of two polarizing lenses and two quarter wave lenses; the polariscope in this arrangement is circular and isochromatic fringe patterns are observed. When the two quarter wave lenses are removed a plane polariscope results and both isochromatic and isoclinic fringe patterns are observed; the former give the magnitude of the stress and the latter the direction of the stress. A high intensity white light is directed to the part under investigation. The light travels through the polarizer and the first quarter wave lens. On reaching the coated model the light travels through the coating, is reflected off a reflective cement, and travels back through the coating, the quarter wave lens, the analyzer, and finally to the observer (Fig 1).

When the coated model is observed under load, a colored pattern similar to those seen in two or three dimensional photoelastic studies is seen. A typical pattern is shown in Figure 2, top, for the area of the posterior soldered joint. A sketch of the interference patterns is shown in Figure 2, bottom, where the zero, first, and second order fringes are indicated. The half-order fringes are yellow, whereas the whole-order fringes occur between red and blue. The spectrum of colors is repeated for each fringe with the wholeorder fringes always at the red to blue transition. The interference patterns permit the determination of the magnitude, as well as the direction of the stresses, in a manner similar to that used in transmission photoelasticity.

The photoelastic material used in this study was a two component material, consisting of a resin, PL-8, and a hardener, PLH-8. * The total amount of plastic resin was determined by the formula $W=18.5 \times$ $A \times t$ where 18.5 is a constant, $W$ is the

\footnotetext{
* Photolastic, Inc, Malvern, Pa.
} 


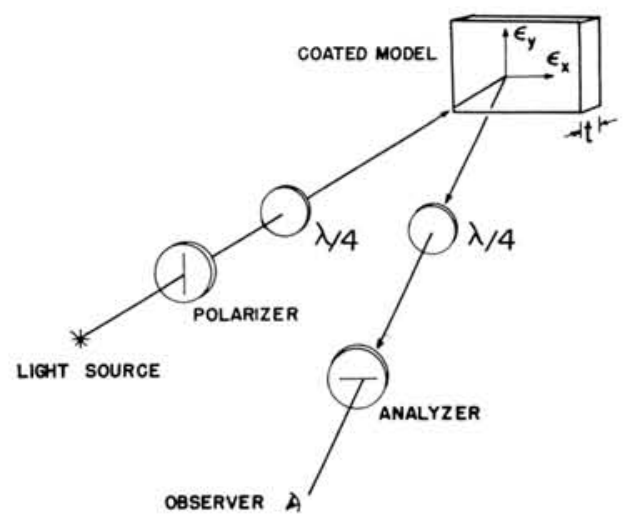

FIG 1.-Sketch of basic reflection photoelastic analyzer.

total amount needed in grams, $t$ is the desired thickness in inches, and $A$ is the area of the sheet in square inches. Once the
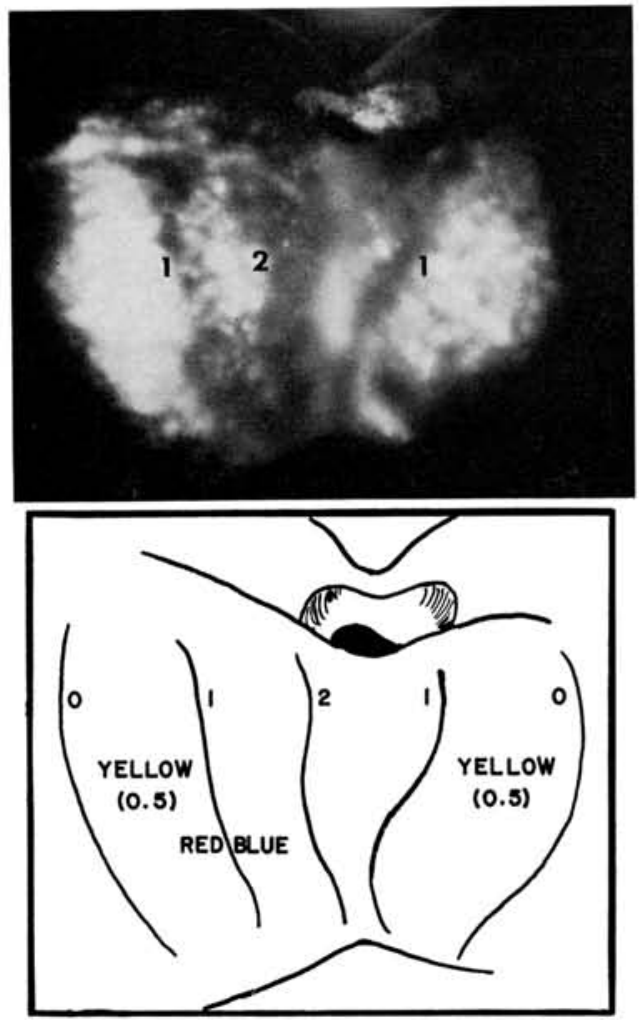

FIG 2.-Top, reflection photoelastic stress pattern loaded with 100 pounds at location 5 and observed at site $A$; numbers refer to isochromatic fringe orders. Bottom, sketch shows location of fringes and colors of various areas. amount of resin is determined, the hardener is measured in parts per hundred ( $\mathrm{pph}$ ); with PLH-8, 14 pph of hardener was used.

The resin and the hardener are heated to approximately $100 \mathrm{~F}$ and then mixed and stirred gently to avoid the development of air bubbles. When a clear mixture is obtained, it is poured carefully on a wellleveled clean Teflon surface. The correct dimensions (length $\times$ width) used earlier for calculating the amount of resin, are set on the Teflon surface with the help of a silicone rubber frame. After the resin is poured, it will flow out and fill the mold and then the mold is covered with a piece of Plexiglas. The liquid plastic goes through several stages during the polymerization cycle. When the plastic becomes stiff, although still flexible, about three hours after the time it is poured, it is "snapped off" the Teflon surface. Part of this semipolymerized sheet is adapted to the structure under investigation and another part is adapted to a calibration bar.

In adapting and contouring the plastic, it is best to begin at one end of the test part to reduce the risk of any air pockets forming between the plastic and the surface of the part. Force should not be used in the adaptation process, because it may stretch the plastic and vary the thickness of the plastic sheet. It should be noted that the working time available for contouring the plastic is approximately 20 minutes. After the plastic has been contoured to the shape of the test part it must be allowed to continue to polymerize for an additional 24 hours before eventually cementing it to the part.

The cement used for bonding the plastic coating to the test part is also a two component material consisting of epoxy resin PC-1 and hardener PCH-1* that must be mixed in the proper proportions. The amount of cement needed is based on the surface to be covered and the layer of cement should not exceed 0.010 inch. Once the sheet is cemented it is allowed to cure for another 12 hours, after which the part is ready to be tested.

Calibration.-Calibration of the photoelastic material is necessary to compute the value of the strain optical coefficient (inch/ inch/fringe). The purpose of calibrating the

\footnotetext{
* Photolastic, Inc, Malvern, Pa.
} 
material is to determine the strain necessary to produce one fringe per unit thickness. The calibrator is a precision instrument that provides an accurate means of determining the strain-optical coefficient $K$. The $K$ factor can be measured to within \pm 0.001 or to within $\pm 1 \%$ for $K=0.100$. As was mentioned earlier, the plastic to be calibrated, $A$ (Fig 3 ), is bonded to an aluminum 2024-T4 bar $(B), 0.250 \pm 0.001$ thick and 1 inch wide. The bar is then introduced in the calibrator and loaded as a cantilever beam by a counterclockwise rotation of the handle $(C)$. The angular position of the loading screw is shown on the precision dial disk $(D)$. The birefringence at the cross on the plastic coating is measured with the basic photoelastic analyzer equipped with a digital compensator.

To establish $f$, the fringe value, and $K$ of the plastic, first the stress on the uncoated beam is calculated. The stress from simple beam theory is

$$
\begin{array}{r}
\sigma_{x}=\frac{6 P L}{b h^{2}}=\frac{6 \times 28.2 \times 6.5}{(1)(1 / 4)^{2}} \\
=17,600 \mathrm{psi}
\end{array}
$$

where $L=6.5$ and $P=28.2$ pounds. The difference in strain is expressed as

$$
\begin{gathered}
\varepsilon_{x}-\varepsilon_{y}=\frac{1+v}{E}\left(\sigma_{x}-\sigma_{y}\right)=\frac{1.33}{10.3 \times 10^{6}} \\
\times 17,600=2270 \times 10^{-6} \mathrm{in} / \mathrm{in}
\end{gathered}
$$

where $v$ is Poisson's ratio $(v=0.33$ for A1), and $\sigma_{y}=0$.

In the middle plane of the plastic coating the strains are

$$
\begin{aligned}
\left(\varepsilon_{x}-\varepsilon_{y}\right)_{\text {plastic }}= & \left.\varepsilon_{x}-\varepsilon_{y}\right) \\
& \text { uncoated structure }
\end{aligned} C_{2}
$$

where $C_{2}$ is obtained from a chart supplied by the maunfacturer of the resin.* For example when the thickness of the plastic, $t_{p}$, is 0.053 inches and the thickness of the aluminum bar, $t_{s}$, is 0.0250 inches, $t_{p} / t_{s}=$ $0.053 / 0.250=0.212$, and from the chart $C_{2}=1.15$. Then $\left(\varepsilon_{x}-\varepsilon_{y}\right) \times C_{2}=2270 \times$

* Reflection Polariscope, Model 030, Instruction Manual, Photoplastic, Inc, Malvern, Pa, p 29.

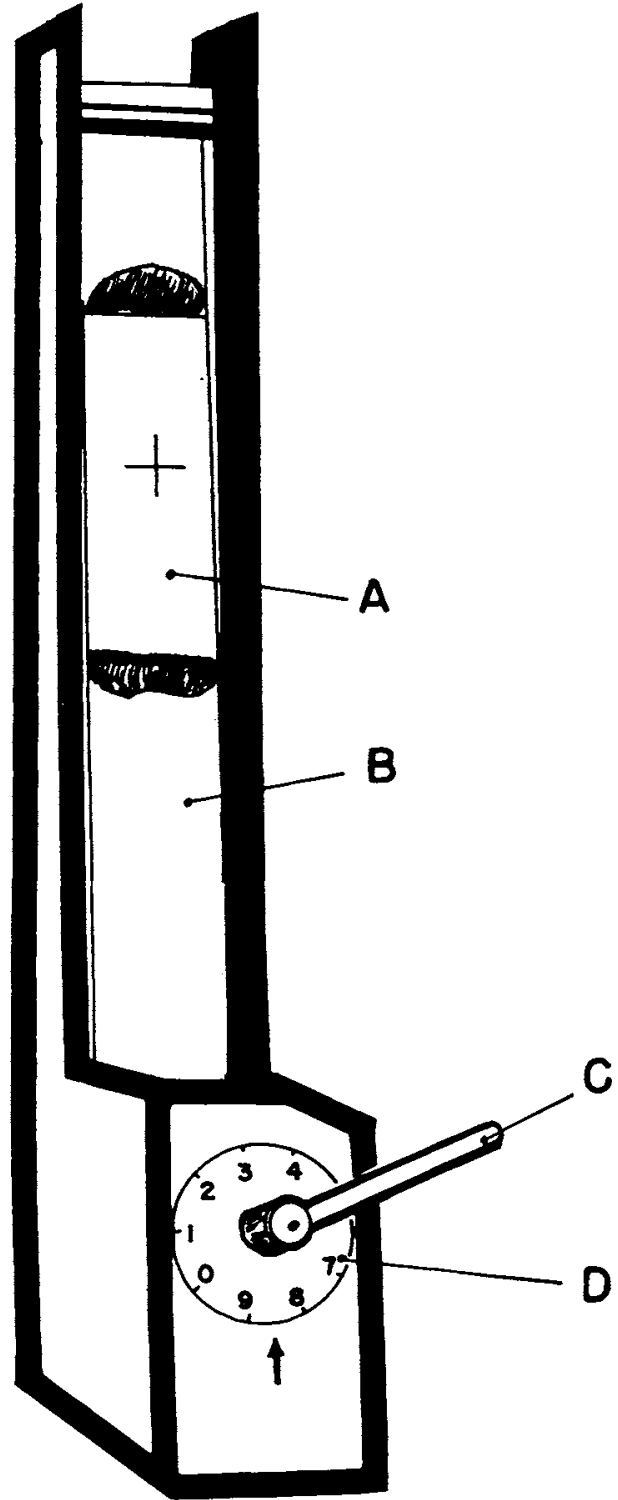

FIG 3.-Sketch of calibrating fixture for determining constants for plastic coating. $A$, plastic to be calibrated; $B$, aluminum bar; $C$, handle; $D$, precision dial disk.

$1.15 \times 10^{-6}=2610 \mathrm{microinch} /$ inch and the fringe value

$$
\begin{aligned}
& f=\frac{\left(\varepsilon_{x}-\varepsilon_{y}\right)_{\text {plastic }}}{N} \\
& \quad=\frac{2610}{0.95}=2750 \mu \mathrm{in} / \text { in }
\end{aligned}
$$


where $N$, the fringe order of 0.95 , was found with help of digital compensator. Then the strain optical coefficient

$$
\begin{aligned}
K=\frac{11.35}{t \times f} & \\
& =\frac{11.35}{0.053 \times 2750}=0.078
\end{aligned}
$$

where 11.35 is a constant.

The properties of the plastic coating and adhesive given by the manufacturer are listed in Table 1 . The experimentally determined $K$ factor of the plastic and adhesive was $K=0.078$.

Once the plastic was calibrated the coated four unit posterior gold bridge was loaded with 100 pounds, with the help of an Instron, at five different locations as shown in Figure 4. $N$, the fringe order, was recorded at three different sites on the lingual and the buccal side. Since the load could not be applied directly on the plastic coating, holes with a diameter of 0.085 inches were drilled at the five loading sites before cementation.

\section{LOADING LOCATIONS}

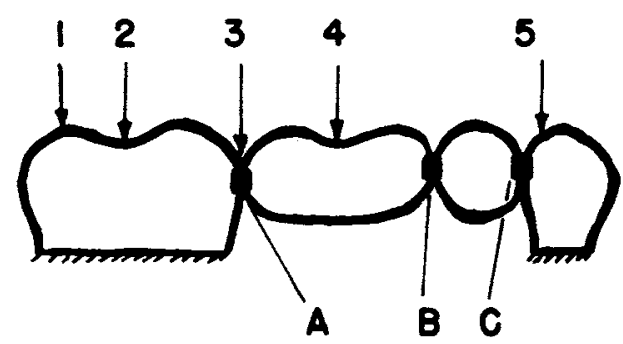

\section{OBSERVED SITES}

Fig 4.-Sketch of four unit gold bridge shows loading locations and observation sites.
The gold bridge was described in an earlier paper. ${ }^{9}$ The silicone lining around the roots of the abutment teeth was replaced after measurements were taken on the lingual side because of flow of the liner. The replacement was necessary because of numerous loadings required to develop the technique, particularly the photographic reproduction of the fringes. The bridge had porcelain facings and the photoelastic coating covered them and the gold surfaces on the buccal aspect of the bridge. Measurements on the buccal surface were taken in a period of a few days since the technique presented no problems at this time.

Color photographs were taken of the interference patterns and the fringe order was established by the use of a digital compensator.

\section{Results}

The fringe order at sites $A, B$, and $C$ on the lingual surface are plotted as a function of the location of a 100 pound concentrated load on the five sites of loading (Fig $5, a$ ). The fringe order is also plotted as a function of the site of observation (Fig $5, b$ ). When the load was moved from the posterior to the anterior positions the fringe order for site $C$ decreased until the load was just anterior to site $C$. The fringe order at site $A$ did not vary greatly but was slightly higher at loading positions 3 and 5 . When the fringe order at site $B$ was determined, it was high when loaded at sites 3 and 4 .

The fringe order at sites $A, B$, and $C$ on the buccal surface are plotted as a function of the location of loading (Fig 6,a) and the observed sites (Fig 6, $b$ ). As the loading site was moved from 1 to 5 , the fringe order at site $A$ increased from 0.5 to 2.0 ; the fringe order at site $B$ increased only when the bridge was loaded at positions 4 and 5 ,

TABLE 1

\begin{tabular}{|c|c|c|c|c|}
\hline & $\begin{array}{c}K \\
\text { Factor } \\
\end{array}$ & $\begin{array}{l}\text { Modulus } \\
\text { of } \\
\text { Elasticity } \\
\text { (psi) }\end{array}$ & $\begin{array}{l}\text { Poisson's } \\
\text { Ratio }\end{array}$ & $\begin{array}{l}\text { Maximum } \\
\text { Elongation }\end{array}$ \\
\hline \multicolumn{5}{|l|}{ Liquid plastic } \\
\hline $\left.\begin{array}{l}\text { Resin PI-8 } \\
\text { Hardener PLH-8 }\end{array}\right\}$ & 0.08 & 420,000 & 0.36 & $3-5 \%$ \\
\hline \multicolumn{5}{|l|}{ Adhesive } \\
\hline $\left.\begin{array}{l}\text { Resin PC-1 } \\
\text { Hardener PCH-1 }\end{array}\right\}$ & . & 450,000 & $\cdots$ & $3-5 \%$ \\
\hline
\end{tabular}

Properties of the Photoelastic Coating and Adhesive 

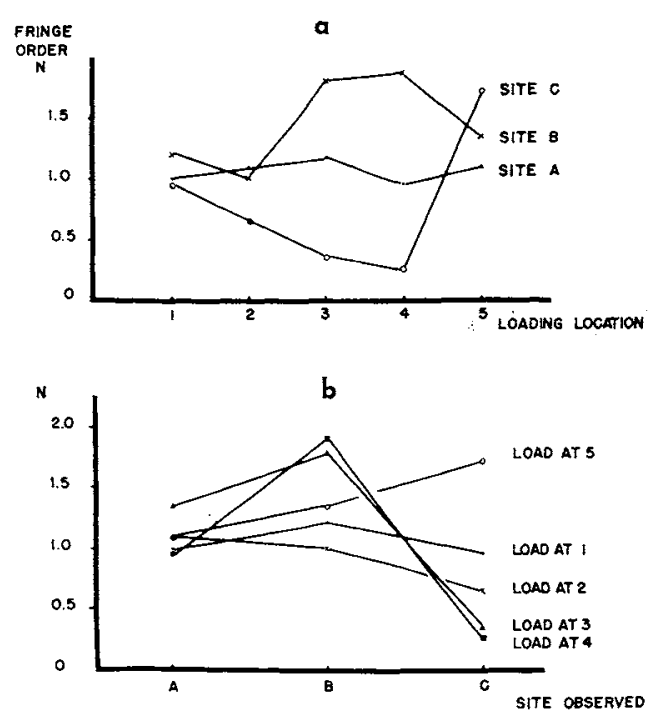

FIG 5.-a, Fringe order on lingual surface as function of loading location at $\mathbf{1 0 0}$ pound load. $b$, Fringe order as function of site of observation.

with the higher value at site 4 . When site $C$ was examined the fringe order increased from loading positions 1 to 3 followed by a decrease at 4 and another increase at 5 .

The principal strains were calculated for several combinations of loading and obser-
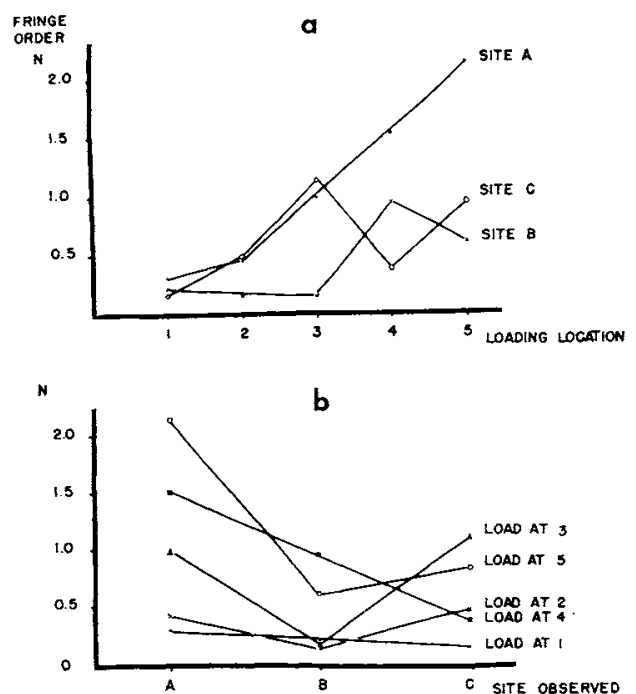

FIG 6.- $-a$, Fringe order on buccal surface as function of loading location at 100 pound load. $b$, Fringe order as function of site of observation. vation sites. The oblique incidence fringe order, $N_{\theta}$, was determined and the principal strains were calculated using the following equations:

$$
\begin{gathered}
\varepsilon_{x}=f\left(1.5 N_{\theta}-N_{\text {norma }}\right) \\
\varepsilon_{y}=f\left(1.5 N_{\theta}-2 N_{\text {norma } 1}\right)
\end{gathered}
$$

$N_{\text {normal }}, N_{\theta}$, and the calculated values for $\varepsilon_{x}$ and $\varepsilon_{y}$ are given in Table 2. For example, for loading location 4 and site of observation $B, \varepsilon_{x}$ was -1595 microinch/inch and $\varepsilon_{y}$ was $-6820 \mathrm{microinch} /$ inch.

\section{Discussion}

The interference patterns observed on the coated bridge confirmed previous observations of two dimensional photoelastic models ${ }^{7}$ that the soldered joints of a bridge are subjected to high strains and that the gingival portion of the pontics are essentially under no strain. These observations result from the nonuniform geometry of the dental bridge.

To interpret the plots of the fringe order vs loading site or loading location it is important to recognize the effect of the silicone rubber lining around the roots of the abutment teeth. To simplify the understanding of the data, the bridge can be thought of as a beam fixed at both ends. The silicone lining permitted the supporting teeth to rotate slightly under load and Figure 7, $a$ illustrates the behavior of the bridge under load. When the load was applied to position 1 , the fringe order, $N$, was a maximum at $B$, but when the load was moved to position 2 less bending occurred because of the shortening of the moment arm. At location 5 it was expected that $N$ at $B$ would be approximately equal to $N$ at $B$ for loading at location 1, and Figure $5, b$ confirms this expectation.

It should be noted that the fringe order, $N$ at $C$, as a result of the load at 5, was higher than $N$ at position $A$ at locations 1 or 2 ; this effect is such because at $C$ there is the combined effect of bending and compression. When the load was applied at position 4 , more bending was caused than at position 3 , and therefore $N$ was larger. The fringe order at $A$ was higher when the bridge was loaded at position 3 because there was the combination of compression and bending.

The silicone lining was replaced before 
TABLE 2

Fringe Order and Principal Strains at a Static 100 Pound Load

\begin{tabular}{|c|c|c|c|c|c|c|c|c|c|}
\hline \multirow{2}{*}{$\begin{array}{c}\text { Load } \\
\text { Location }\end{array}$} & \multirow{2}{*}{$\begin{array}{c}\text { Site } \\
\text { Observed }\end{array}$} & \multicolumn{4}{|c|}{ Lingual } & \multicolumn{4}{|c|}{ Buccal } \\
\hline & & $N_{\text {normal }}$ & $N_{\theta}$ & $\epsilon_{x} \times 10^{-6}$ & $\epsilon_{y} \times 10^{-6}$ & $\overline{N_{\text {normal }}}$ & $N_{\theta}$ & $\epsilon_{x} \times 10^{-\infty}$ & $\epsilon_{y} \times 10^{-6}$ \\
\hline 1 & $A$ & 1.00 & & & & 0.32 & & & \\
\hline 1 & $B$ & 1.20 & & & & 0.23 & & & \\
\hline 1 & $C$ & 0.95 & & & & 0.16 & & & \\
\hline 2 & $A$ & 1.10 & & & & 0.44 & & & \\
\hline 2 & $B$ & 1.00 & & & & 0.15 & & & \\
\hline 2 & $C$ & 0.65 & & & & 0.50 & & & \\
\hline 3 & $A$ & 1.40 & & & & 1.00 & & & \\
\hline 3 & $B$ & 1.80 & 0.80 & -1650 & -6600 & 0.15 & & & \\
\hline 3 & $C$ & 0.35 & & & & 1.15 & & & \\
\hline 4 & $A$ & 0.95 & & & & 1.55 & 0.68 & -1458 & -5725 \\
\hline 4 & $B$ & 1.90 & 0.88 & -1595 & -6820 & 0.95 & & & \\
\hline 4 & $C$ & 0.25 & & & & 0.40 & & & \\
\hline 5 & $A$ & 1.10 & & & & 2.30 & 1.0 & -2200 & -8525 \\
\hline 5 & $B$ & 1.35 & & & & 0.62 & & & \\
\hline 5 & $C$ & 1.70 & & & & 0.95 & & & \\
\hline
\end{tabular}

measurements were made on the buccal surface of the bridge. The change of the lining caused a change in the behavior of the bridge, as evidenced by the data in Figure $6, a$ and $b$. The bridge did not function as a fixed beam but more as a cantilever bridge as shown in Figure $7, b$. The term cantilever implies that the premolar abutment had more freedom of movement compared with the molar. When the load was placed at
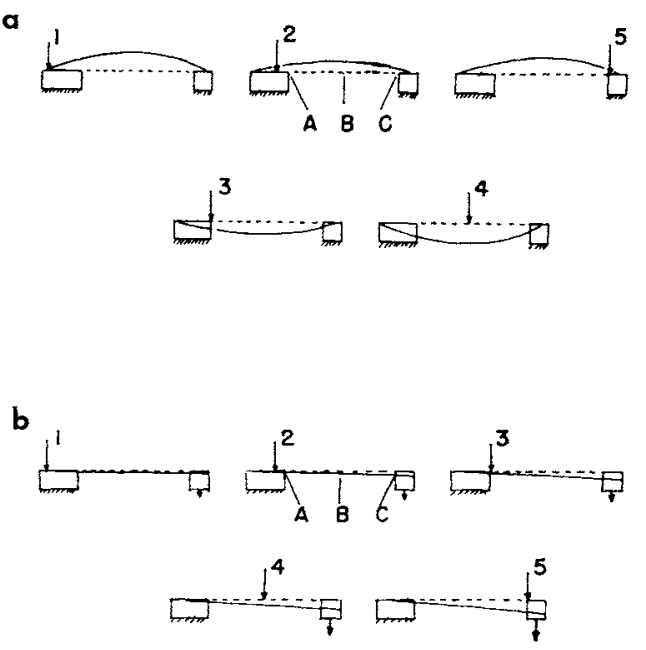

FIG 7.- $a$, Sketch indicates behavior of bridge on lingual surface when roots of abutments were well supported. $b$, Sketch shows the bebavior of bridge on buccal surface when roots of abutments were less well supported. Increasing length of arrows indicates increasing deflections. positions 1 and 2, little change was observed. At location 3, high strains were registered at site $A$ because of bending and compression. When the loading was at positions 4 or 5 , high strains were observed at $A$. This behavior is similar to that exhibited by a cantilever beam.

The differences observed for the two parts of the experiment (lingual and buccal observations) can be explained in the following manner. The lingual observations were made after numerous preliminary loadings during which the technique was developed. During this period the roots of the teeth became well adapted to the silicone as a result of the flow of the lining. As a result, the bridge functioned as if it were fixed at both ends. After replacement of the lining, the measurements on the buccal side were made before flow of the lining occurred. The bridge, therefore, functioned as a cantilever with the fixed end at the larger abutment.

\section{Conclusions}

Reflection photoelasticity was shown to be a useful tool for determining surface strains on dental structures. The method has the advantages of permitting the use of the actual structure, in this study a four unit bridge, and providing an overall visual display of the location and distribution of the strains. The principal strains can be calculated easily from recordings of the interference patterns obtained in normal and oblique light. Improvement in the 
method would result from the development of a more sensitive photoelastic plastic coating.

The strain concentration was at the soldered joints. The magnitude of the strain and the behavior of the bridge were dependent on the support provided by the roots of the abutment teeth. When the roots of the abutment teeth were extremely well adapted to the lining, the bridge functioned as a beam fixed at both ends. When the roots of the abutment teeth adapted only reasonably well to the lining, the bridge functioned as a cantilever beam fixed at the end with the best support.

\section{References}

1. Craig, R.G.; El-Ebrashi, M.K.; LePeak, P.J.; and PeYTON, F.A.: Experimental Stress Analysis of Dental Restorations. I. Twodimensional Photoelastic Stress Analysis of Inlays, J Prosth Dent 17:277-291, 1967.

2. Craig, R.G.; El-Ebrashi, M.K.; and Peyton, F.A.: Experimental Stress Analysis of Dental Restorations. II. Two-dimensional Photoelastic Stress Analysis of Crowns, J Prosth Dent 17:292-302, 1967.

3. El-Ebrashi, M.K.; Craig, R.G.; and Peyton, F.A.: Experimental Stress Analysis of Dental Restorations. III. The Concept of the
Geometry of Proximal Margins, J Prosth Dent 22:333-345, 1969.

4. El-Ebrashi, M.K.; Craig, R.G.; and Peyton, F.A.: Experimental Stress Analysis of Dental Restorations. IV. The Concept of Parallelism of Axial Walls, J Prosth Dent 22:346353, 1969.

5. El-Ebrashi, M.K.; Craig, R.G.; and Peyton, F.A.: Experimental Stress Analysis of Dental Restorations. V. The Concept of Occlusal Reduction and Pins, J Prosth Dent 22:565-577, 1969.

6. El-Ebrashi, M.K.; Craig, R.G.; and Peyton, F.A.: Experimental Stress Analysis of Dental Restorations. VI. The Concept of Proximal Reduction in Compound Restorations, J Prosth Dent 22:663-670, 1969.

7. El-Ebrashi, M.K.; Craig, R.G.; and Peyton, F.A.: Experimental Stress Analysis of Dental Restorations. VII. Structural Design and Stress Analysis of Fixed Partial Dentures, J Prosth Dent 23:177-186, 1970.

8. Dally, J.W., and Riley, W.F.: Experimental Stress Analysis, New York: McGrawHill, 1965, pp 280-305.

9. Tillitson, E.W.; Craig, R.G.; Farah, J.W.; and PEyToN, F.A.: Experimental Stress Analysis of Dental Restorations. VIII. Surface Strains on Gold and Chromium Fixed Partial Dentures. J Prosth Dent 24:174-180, 1970. 